\title{
Ligand effect on the oxidative addition of dioxygen to $\operatorname{gold}(\mathrm{I})$-hydride complexes
}

\author{
Carlo Alberto Gaggioli ${ }^{a}$, Leonardo Belpassi ${ }^{b^{*}}$, Francesco Tarantelli $^{b c}$,
} Jeremy N. Harvey ${ }^{d}$, Paola Belanzoni ${ }^{b c^{*}}$

a Department of Chemistry, Chemical Theory Center and Supercomputing Institute, University of Minnesota, 207 Pleasant Street SE, 55455-0431, Minneapolis, Minnesota, USA

${ }^{b}$ Institute of Molecular Science and Technologies (ISTM) - CNR, via Elce di Sotto 8, 06123 Perugia, Italy E-mail: leonardo.belpassi@cnr.it

${ }^{c}$ Department of Chemistry, Biology and Biotechnology, University of Perugia, via Elce di Sotto 8, 06123 Perugia, Italy E-mail: paola.belanzoni@unipg.it

${ }^{d}$ Department of Chemistry, KU Leuven, Celestijnenlaan 200F, B-3001 Heverlee, Belgium

\section{Abstract}

The ligand effect on the recently uncovered feasible oxidative addition reaction of $\mathrm{O}_{2}$ on $[\mathrm{LAuH}]$ complexes has been investigated for a series of fifteen ligands. The activation barriers of this spin-forbidden reaction have been estimated at the minimum energy crossing points (MECP, relativistic scalar level) between the adiabatic triplet (reactants spin state) and singlet (product spin state) potential energy surfaces (PES) and calculated at the transition states by including Spin Orbit Coupling (SOC) effects, as applied for the mechanistic study of this reaction in a previous work of us [Chem Sci. 2016, 7, 70347039]. We find a sizeable effect of the ligand on the activation barriers, and some of the stronger electron donating phosphines are predicted to induce the highest catalyst efficiency. The inclusion of SOC effects lowers the activation barriers by about 3 $\mathrm{kcal} / \mathrm{mol}$ systematically with respect to the MECP values independently from the ligandtype. We used the Charge-Displacement (CD) analysis for quantifying the net electron charge donation from the ligand $\mathrm{L}$ towards the metallic fragment $\mathrm{AuH}$ in $[\mathrm{LAuH}]$ series, and surprisingly only a poor correlation has been found between the net electron donor character of $\mathrm{L}$ and the activation barriers. Application of the CD-NOCV (Natural Orbitals for Chemical Valence) approach, which allows to quantify the Dewar-Chatt-Duncanson (DCD) L-AuH bond components, suggests that the ligand effect on the activation barriers is not easily predictable on the basis of the sole electronic properties of the ligand and 
depends significantly on the ligand nature, carbene- or phosphine-type. We show that for both phosphine and carbene ligand subsets however the $\sigma$ donation component of the L$\mathrm{AuH}$ bond quantitatively accounts for the ligand effect on the activation energy barriers (larger $\sigma$-donor capability of $\mathrm{L}$ correlates with a smaller activation barrier), whereas the $\pi$ back-donation, strongly affected by geometrical rearrangement, is a poor reactivity descriptor ( $\pi$ acceptor properties of the ligand $\mathrm{L}$ in the linear [LAuH] complexes are not transferable to the trigonal $\left[\mathrm{LAuH}\left(\mathrm{O}_{2}\right)\right]$ transition state structures).

\section{Introduction}

The chemistry of gold hydrides has received in the last years increased attention, both experimentally and theoretically, ${ }^{1,2,3,4,5}$ focusing on their stability and versatility. Within this field, Bochmann and co-workers ${ }^{6}$ reported the $\mathrm{O}_{2}$ addition to the gold(I)-hydride bond reaction in the [(IPr)AuH] (IPr = 1,3-bis(2,6-diisopropylphenyl)imidazol-2-ylidene) complex which was shown to be feasible under mild conditions, forming a hydroperoxide. The reaction occurs in solution using $\mathrm{C}_{6} \mathrm{D}_{6}$ as solvent, a temperature range of $25-52^{\circ} \mathrm{C}$, through exposure to a $\mathrm{O}_{2}$ pressure of 1-9 bar for 4-48 $\mathrm{h}$. Typically, under 1 bar of $\mathrm{O}_{2}$ at $23^{\circ} \mathrm{C}$ full conversion of the hydride was observed after $48 \mathrm{~h}$, giving a ratio of [(IPr)AuOOH] and [(IPr)AuOH] compounds of about 1:3, suggesting slow decomposition of hydroperoxide into hydroxide species, with release of $\mathrm{O}_{2}$. In experiments, a rate law with first-order dependence on the concentration of hydride and on the partial pressure of $\mathrm{O}_{2}$ was found, although only relatively few $\mathrm{O}_{2}$ pressures were used for measurements so partial second-order character cannot be completely ruled out. The estimated experimental activation parameters are $\Delta \mathrm{H}^{\#}=5.0 \mathrm{kcal} / \mathrm{mol}, \Delta \mathrm{G}^{\#}=22.9 \mathrm{kcal} / \mathrm{mol}$, and $-\mathrm{T}$ $\Delta \mathrm{S}^{\#}=17.9 \mathrm{kcal} / \mathrm{mol}$. The unexpectedly high experimental entropic activation parameter suggests the possibility that a third species (solvent, counterion, or additive) could be involved in the rate-determining step of the reaction. Although the hydride species was directly observed, ${ }^{7}$ attempts to crystallize the hydroperoxide under an atmosphere of oxygen gave single crystals of the binuclear peroxide $[(\operatorname{IPr}) \mathrm{Au}]_{2}\left(\mu-\kappa^{1}: \kappa^{1}-\mathrm{O}_{2}\right){ }^{6}$ The reaction of the hydride with $\mathrm{O}_{2}$ to give hydroperoxide (and hydroxide) was observed by 
monitoring the proton resonance through ${ }^{1} \mathrm{H}$ NMR spectra. ${ }^{6}$ Triggered by this finding, in a recent work we theoretically investigated the mechanism of this reaction, ${ }^{8}$ demonstrating that the oxidative addition of $\mathrm{O}_{2}$ to the gold center to produce a formal gold(III) intermediate followed by reductive elimination (or recombination) is unexpectedly the kinetically favored path. The rate determining step (RDS) of the oxidative addition/recombination mechanism, namely the oxidative addition step, is shown in Figure 1. The following steps leading to the final product (recombination) occur easily through intermolecular routes, where a third species (solvent, counterion, or additive) could be involved. We mention here that a hypothetical oxidative addition/recombination mechanism involving two $\mathrm{O}_{2}$ molecules has been found to be also feasible (see Figure 1).8

As already mentioned, the RDS is formed by the oxidative addition step of $\mathrm{O}_{2}$ to the gold center. This step involves reactants in a spin-triplet state, whereas the product is a singlet, so it is a spin-forbidden step, and standard computational methods for transition state (TS) optimization are not applicable. ${ }^{9}$ Accordingly, as in our previous work, ${ }^{8}$ we have used two alternative procedures to locate the barrier to reaction. First, we have located the minimum energy crossing point (MECP, calculated at a relativistic scalar level) between the triplet (reactant spin state) and singlet (product spin state) potential energy surfaces (PES). Next, we have located the saddle-point or transition state TS on the Spin-Orbit Coupled potential energy surface (TS SOC). By including terms for spin-orbit coupling in the Kohn-Sham procedure, we are able to describe the region around the oxidative addition TS, where the spin-state character is intermediate between singlet and triplet. We should recall herein that, whereas the MECP is not a stationary point, the TS SOC allows for the calculation of the activation energy barrier, the latter being only estimated at the MECP. In Figure 2, the state-of-the-art literature about oxidative addition to gold(I) complexes is summarized, as reported by Bourissou and co-workers. ${ }^{10}$ Recent studies have substantiated the ability of gold(I) complexes to undergo oxidative addition of $\mathrm{C}\left(\mathrm{sp}^{3}\right)-\mathrm{X}$ as well as $\mathrm{C}\left(\mathrm{sp}^{2}\right)-\mathrm{X}$ bonds $(\mathrm{X}=$ halide $)$ and apolar $\mathrm{E}-\mathrm{E} \sigma$ bonds $(\mathrm{E}=\mathrm{Si}, \mathrm{Sn}, \mathrm{C})$, provided that a suitable modification of their starting structure is achieved, thus suggesting that electronic and structural features can play a major role in their reactivity. ${ }^{11}$ For $[\mathrm{LAuX}](\mathrm{X}=$ halide $)$ complexes, $\mathrm{X}^{-}$has to be removed before oxidative addition can occur (Fig.2 a), ${ }^{12,13,14}$ whereas for $[\mathrm{LAuL}]^{+}$complexes, ligands with a particular bonding pattern which produces a bent structure must be used, in order to "pre-organize" gold for 
oxidation (since $\mathrm{Au}(\mathrm{III})$ product has a square planar geometry) (Fig.2 b). ${ }^{15,16,17,18,19,20}$ Within this scenario our previous work indeed pointed out an additional pathway to reactive gold(I) complexes, since $\mathrm{O}_{2}$ oxidative addition has been shown to occur directly from $[\mathrm{LAuX}]$ complex $(\mathrm{X}=\mathrm{H})$ without removing hydride in advance (Fig. 2c).

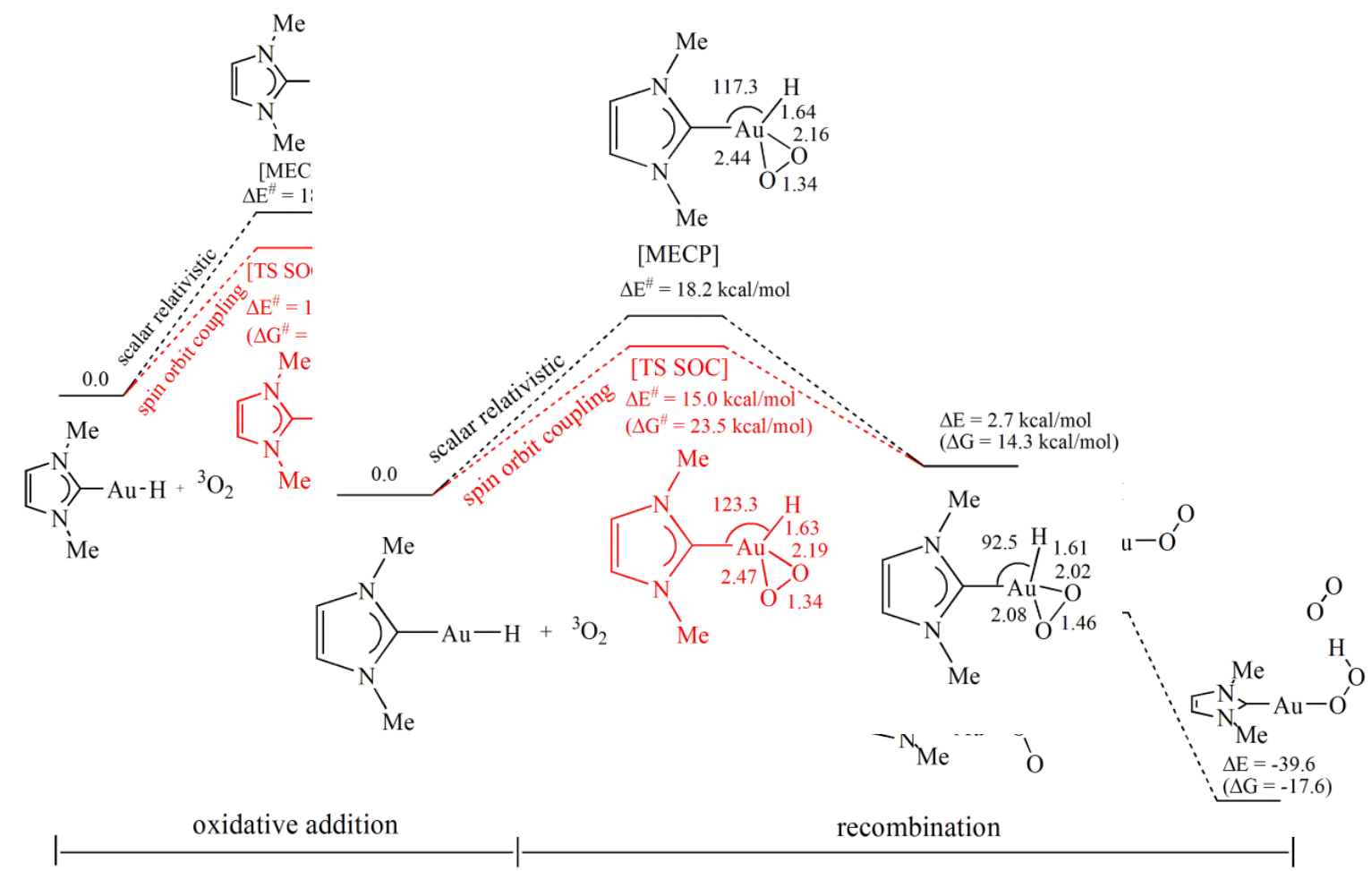

Figure 1: Top) Oxidative addition/rearrangement reaction mechanism for the insertion of $\mathrm{O}_{2}$ into the $[\mathrm{LAu}-\mathrm{H}]$ ( $\mathrm{L}=\mathrm{NHC} \_\mathrm{Me}_{2}$ )bond (relative energies in $\mathrm{kcal} / \mathrm{mol}$ ); Bottom) Zoomed-out oxidative addition step (RDS) of the above mechanism, highlighting the MECP (black line) and TS SOC (red line) approaches and the main geometrical parameters (in $\AA$ ). 
a)

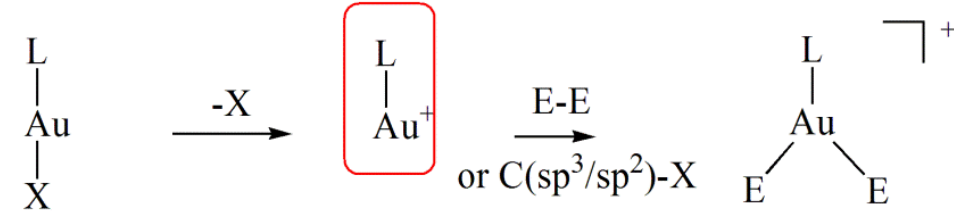

b)

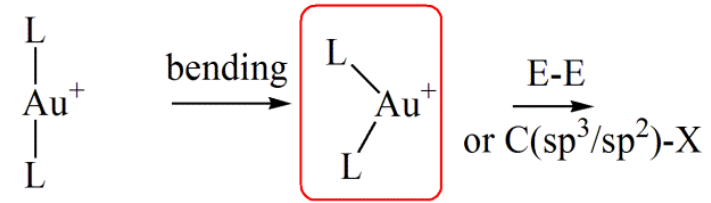<smiles>[3H][Al]([3H])([3H])[3H]</smiles>

c)

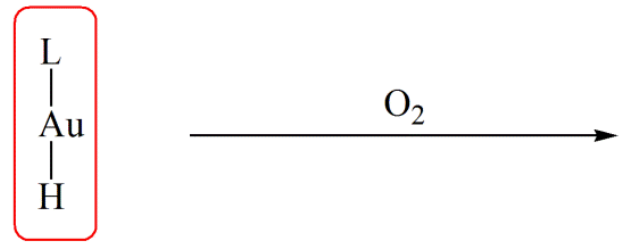<smiles>I[AlH]1OO1</smiles>

Figure 2: Reactive gold(I) complexes for oxidative addition. Available approaches: a) halide abstraction from [L-Au-X]; b) bending of the L-Au-L angle from [L-Au-L] ${ }^{+}$c) directly from $[\mathrm{L}-\mathrm{Au}-\mathrm{H}]$ complexes with dioxygen.

This intriguing result has motivated us to analyze the ligand effect on the rate determining step of the oxidative addition, as shown in Figure 1. This work is aimed at exploring how the activation barriers of the direct addition of $\mathrm{O}_{2}$ to $[\mathrm{L}-\mathrm{Au}-\mathrm{H}]$ are influenced by the ligand nature. The sketch of the analyzed ligands is shown in Figure 3.

CO<smiles>[X][X]1[X]N([R])C=[N+]1[R]</smiles>

NHC_Me $2: \mathrm{R}=\mathrm{Me} ; \mathrm{X}=\mathrm{CH}$

IPr: $\mathrm{R}=2,6-\mathrm{Pr}^{\mathrm{i}}-\mathrm{C}_{6} \mathrm{H}_{3} ; \mathrm{X}=\mathrm{CH}$

NHC_Me 2 sat: $\mathrm{R}=\mathrm{Me} ; \mathrm{X}=\mathrm{CH}_{2}$

NHC_H: $\mathrm{R}=\mathrm{H} ; \mathrm{X}=\mathrm{CH}$

NHC_F: $\mathrm{R}=\mathrm{H} ; \mathrm{X}=\mathrm{CF}$

NAC: $\mathrm{R}=\mathrm{CH}_{3} ; \mathrm{X}=\mathrm{H}$

$\mathrm{PH}_{3}: \mathrm{R}=\mathrm{H}$

$P_{3}: R=F$

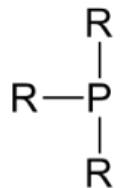

$\mathrm{PMe}_{3}: \mathrm{R}=\mathrm{Me}$

$\mathrm{P}(\mathrm{OMe})_{3}: \mathrm{R}=\mathrm{MeO}$

$\mathrm{PPh}_{3}: \mathrm{R}=\mathrm{Ph}$

p-OMe: $\mathrm{R}=(p-\mathrm{MeO}-\mathrm{Ph})$

p-Me: $\mathrm{R}=(p-\mathrm{Me}-\mathrm{Ph})$

$\mathbf{p}-\mathrm{CF}_{3 \dot{5}} \mathrm{R}=\left(p-\mathrm{CF}_{3}-\mathrm{Ph}\right)$ 
Figure 3: sketch of the studied ligands

We investigated a series of fifteen ligands, chosen to span a large range of electron donor/acceptor properties, including carbon monoxide, six different carbenes and eight different phosphines. For carbenes, we selected the widely used N-Heterocyclic-Carbene (NHC) structure and we modified the groups bonded to the nitrogen atoms (NHC_Me IPr) and the groups attached to the NHC backbone (NHC_H, NHC_F) and we saturated the ring (NHC_Me $\mathrm{Me}_{2}$ sat). Note that IPr is the ligand actually employed in the Bochmann's experiment. 2 We also chose an N-Acyclic-Carbene (NAC) structure. For phosphines, we singled out a $\mathrm{PR}_{3}$ structure, containing fluorine or hydrogen atoms $\left(\mathrm{PF}_{3}, \mathrm{PH}_{3}\right)$, methyl $\left(\mathrm{PMe}_{3}\right)$, methoxy $\left(\mathrm{P}(\mathrm{OMe})_{3}\right)$ or aromatic substituents such as phenyl $\left(\mathrm{PPh}_{3}\right)$ and substituted phenyl groups ( $\mathrm{p}-\mathrm{OMe}, \mathrm{P}-\mathrm{Me}, \mathrm{p}-\mathrm{CF}_{3}$ ).

In this study we use Charge-Displacement analysis via Natural Orbitals for Chemical Valence (CD-NOCV) approach ${ }^{21}$ Error! Bookmark not defined. to quantify the $\sigma$-donation and $\pi$ back-donation components of the L-AuH bond within the Dewar-Chatt-Duncanson (DCD) model in an attempt to correlate the ligand L electronic properties in the [LAuH] complexes and the oxidative addition activation barriers. We will demonstrate that the ligand effect on the activation barriers depends on the ligand nature, carbene- or phosphine-type, with the aromatic phosphine predicted as the most efficient ligand in the $\mathrm{O}_{2}$ oxidative addition to [LAuH]. We will show that the $\sigma$ electron donor character of the ligand $\mathrm{L}$ in the $[\mathrm{LAuH}]$ complexes acts as the crucial factor in driving the oxidative addition, whereas the ligand $\pi$ electron acceptor character has an erratic effect, due to the non-transferable description of the metal fragment to ligand back-bonding interaction from the linear $[\mathrm{LAuH}]$ to the "trigonal" $\left[\mathrm{LAuH}\left(\mathrm{O}_{2}\right)\right]$ transition state structures.

The paper is organized as follows. We first describe the calculation set up and the CDNOCV approach used to quantify the electronic properties of the ligands. The main results concerning the ligand effect on the oxidative addition reaction barriers and on the $\mathrm{L}-\mathrm{AuH}$ bond in $[\mathrm{LAuH}]$ complexes as well as on the $\mathrm{L}-\mathrm{AuH}\left(\mathrm{O}_{2}\right)$ bond at the reaction 
transition state $\left[\mathrm{LAuH}\left(\mathrm{O}_{2}\right)\right]$ structures are subsequently presented. Finally, the work is summarized in the Conclusion.

\section{Computational Details}

The mechanistic study has been carried out by DFT calculations using the ADF 2012.01 program package ${ }^{22}$, with the following details: BP86 functional ${ }^{23}$, Grimme3 BJ damping dispersion effect (DFT-D3-BJ) ${ }^{24}$, a Slater-Type DZP quality (TZP for gold) basis set (core small) and a ZORA Hamiltonian ${ }^{25}$ to include relativistic effects. We employed either the scalar or the spinorbit ZORA Hamiltonian, the latter used in order to take into account spin orbit coupling (SOC) effects. The calculation of the Minimum Energy Crossing Points (MECP) has been done using the program developed by one of $\mathrm{us}^{26}$ interfaced with the ADF package, with the computational details described above. This computational setup has been validated in our previous work8 where the possible error bars one would get by changing any basis set, exchange-correlation functional, D3-BJ dispersion correction or solvation (benzene) item have been assessed.

For the computation of the electron density for the bond analysis, we use ADF 2012.01 program package, with BP86 functional, a Slater-Type TZ2P quality basis set (core small) and a ZORA Hamiltonian (scalar) to include relativistic effects. All calculations have been performed in gas phase.

\section{Charge Displacement Function.}

An efficient way to analyze thoroughly the rearrangement of the electron density taking place upon bond formation between two fragments is to use the Charge-Displacement (CD) approach, ${ }^{27}$ which allows to estimate the exact amount of electron charge that, upon the formation of a bond, is displaced from a fragment to another. ${ }^{28,29}$ The $\mathrm{CD}$ analysis is today a well established and successful tool for chemical bond analysis in a wide variety of context; it has been successfully used, for example, to study the chemical bond between gold(I) and the noble gases ${ }^{27}$ and bonds in organometallic chemistry. ${ }^{30,31,32}$ Mathematically, the CD function is defined as: 
$\Delta q(\mathrm{z})=\int_{-\infty}^{\infty} d x \int_{-\infty}^{\infty} d y \int_{-\infty}^{z} \Delta \rho\left(x, y, z^{\prime}\right) d z^{\prime}$

Here $\mathrm{z}$ is the axis of interest, typically one joining the interacting species (in our work, the axes that passes through the ligand atom bonded to gold and gold) and $\Delta \rho\left(x, y, z^{\prime}\right)$ is defined as the electron density of the molecule minus the sum of the electron densities of the isolated noninteracting fragments placed at the same position as in the molecule. Thus $\Delta q(\mathrm{z})$ measures, at each point of the $\mathrm{z}$ axis, the number of electrons that, upon formation of the bond between the two fragments, moves across a plane perpendicular to the internuclear axis through the $\mathrm{z}$ point (defined as Charge Transfer, CT). A positive (negative) value of $\Delta \mathrm{q}(\mathrm{z})$ indicates electrons moving towards the decreasing (increasing) z. Furthermore, by looking at the slope, one can immediately deduce regions of charge accumulation (positive slope) or charge depletion (negative slope). To have a numerical estimate of the $\mathrm{CT}$, the value of the $\mathrm{CD}$ curve can be taken at any plausible inter-fragment boundary along z. Our standard choice is to take the CT at the so-called "isodensity boundary", i.e. the point along $\mathrm{z}$ where the electron densities of the non interacting fragments become equal. All the CTs used in this work refer to the CT taken at the isodensity boundary.

When the system under study and its fragments do not satisfy the symmetry requirements (as it happens for systems without symmetry, for instance), the Natural Orbital for Chemical Valence theory (NOCV) scheme is used to partition the electron density difference into additive contributions, giving a quantitative picture of donation and backdonation charge displacements. ${ }^{21}$ In the NOCV framework, ${ }^{33}$ the charge rearrangement taking place upon formation of a molecule $\mathrm{AB}$ from fragments $\mathrm{A}$ and $\mathrm{B}$ is obtained from the occupied orbitals of A and B suitably orthogonalized to each other and renormalized (for details see ref. ${ }^{21,33}$ ). The resulting density rearrangement $\Delta \rho$ ' can be written in terms of NOCV pairs, i.e. the eigenfunctions $\varphi_{ \pm \mathrm{k}}$ of the so-called "valence operator" of Nalewajski and Mrozek valence theory, ${ }^{34}$ as follows

$\Delta \rho^{\prime}=\sum_{k} \Delta \rho_{\mathrm{k}}^{\prime}$

It is worth stressing here, however, that only a small subset of these NOCV pairs actually contributes to the overall charge rearrangement $\Delta \rho$ ' because a large part of them presents eigenvalues close to zero. ${ }^{35}$ NOCV method has been applied with success for the characterization of transition metal compounds ${ }^{36}$ and for disentangling donation and 
back-donation in the $\mathrm{CD}$ function of non-symmetric systems containing NHC-Au bond. $^{37,38}$

\section{Results and discussion}

\section{Ligand effect on the oxidative addition activation barriers}

We start the analysis of the $[\mathrm{LAuH}]+\mathrm{O}_{2}$ reaction by both estimating the activation barriers through the MECP location and calculating activation barriers via TS SOC, for all the ligands listed in Fig.3. Corresponding data are collected in Table 1. The ligand effect on the oxidative addition activation barrier is found to be remarkable, as shown in Figure 4.

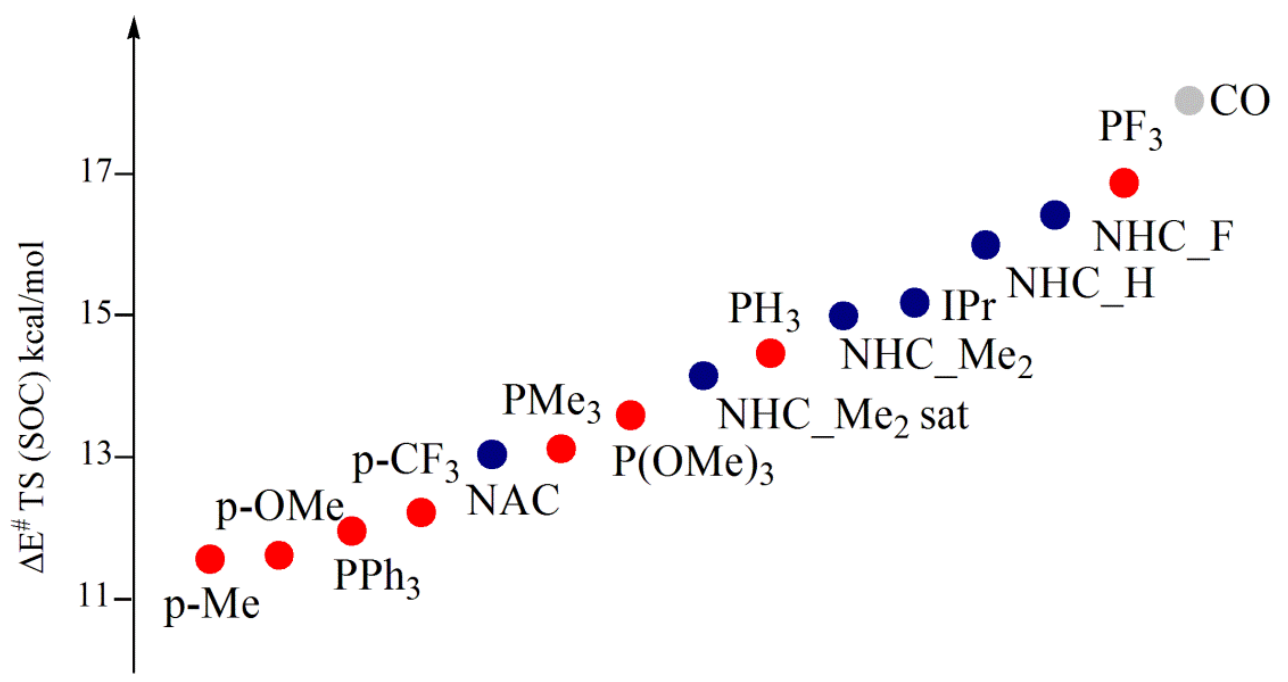

Figure 4: Activation energy barriers computed by the transition states including SOC effects (TS SOC) for all the ligands in Fig.3

We note that the activation barriers computed by TS SOC span a range of about 6-7 $\mathrm{kcal} / \mathrm{mol}$ along the ligand set. This range of $\Delta \mathrm{E}^{\neq}$is expected to produce a huge effect on the experimental reaction rate, according to the exponential relationship between activation barrier and TOF values (see for instance, ref. ${ }^{39,40,41}$ ). More acidic ligands display higher barriers, with $\mathrm{CO}$ showing the highest one $(18.1 \mathrm{kcal} / \mathrm{mol})$ followed by $\mathrm{PF}_{3}$ 
(16.8 kcal/mol). The carbene-based ligands span a somewhat narrower range of activation barrier values than that calculated for phosphine-based ligands $(3.3 \mathrm{vs}$. $5.3 \mathrm{kcal} / \mathrm{mol}$, respectively), with the NHC bearing fluorine (NHC.F) showing the highest barrier (16.4 $\mathrm{kcal} / \mathrm{mol})$, and the acyclic NAC and saturated NHC_ $\mathrm{Me}_{2}$ sat the lowest $(13.1 \mathrm{kcal} / \mathrm{mol}$ and $14.2 \mathrm{kcal} / \mathrm{mol}$, respectively). Among the phosphine-based ligands, we find that $\mathrm{PPh}_{3}$ as well as the more electron donating ligands such as p-OMe or p-Me result in the lowest barriers among all of the analyzed ligands $(11.9,11.6$ and $11.5 \mathrm{kcal} / \mathrm{mol}$, respectively). From Figure 4 two important results can be highlighted: i) based on the accessible activation energy barrier values calculated for the ligand series, a further evidence that the reaction of $\mathrm{O}_{2}$ with [LAuH] indeed occurs through the oxidative addition mechanism, as found in our previous work;8 ii) prediction that the use of an electron donating phosphine accelerate the reaction. This last finding is particularly relevant and it deserves to be still verified experimentally, since, as mentioned above, to date only carbene ligands (IPr) have been used for oxidative addition with [LAuH] complexes. 6

From a methodological point of view, we correlate the two reaction barriers calculated using MECP and TS SOC in Figure 5.

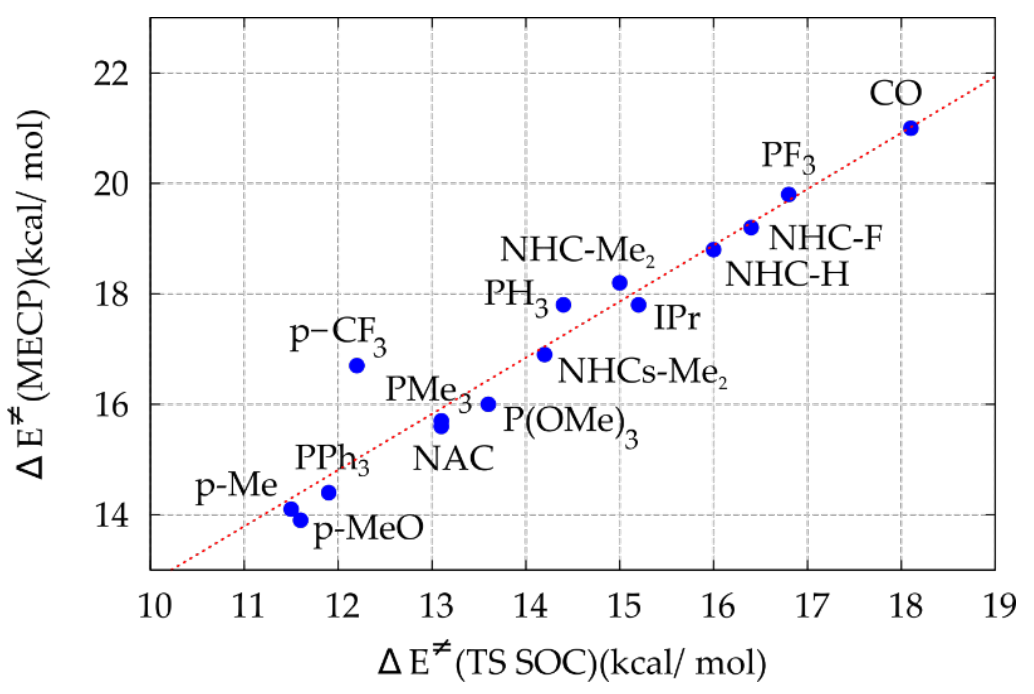

Figure 5: Plot of the activation barriers computed using MECP (as an estimate of $\Delta \mathrm{E}^{\ddagger}$ ) and activation barriers computed by the transition states including SOC effects $\left(\mathrm{R}^{2}=0.937, \mathrm{y}=1.01 \mathrm{x}+2.74\right)$. 


\begin{tabular}{|l|l|l|l|}
\hline Entry & Ligand & $\begin{array}{l}\Delta \mathrm{E}^{\ddagger} \mathrm{MECP} \\
(\mathrm{kcal} / \mathrm{mol})\end{array}$ & $\begin{array}{l}\Delta \mathrm{E}^{\ddagger} \mathrm{TS} \mathrm{SOC} \\
(\mathrm{kcal} / \mathrm{mol})\end{array}$ \\
\hline 1 & $\mathrm{p}-\mathrm{OMe}$ & 13.9 & 11.6 \\
\hline 2 & $\mathrm{PPh}_{3}$ & 14.4 & 11.9 \\
\hline 3 & $\mathrm{PF}_{3}$ & 19.8 & 16.8 \\
\hline 4 & $\mathrm{CO}$ & 21.0 & 18.1 \\
\hline 5 & $\mathrm{PH}_{3}$ & 17.8 & 14.4 \\
\hline 6 & $\mathrm{P}_{(\mathrm{OMe})_{3}}$ & 16.7 & 13.6 \\
\hline 7 & $\mathrm{PMe}_{3}$ & 15.7 & 13.1 \\
\hline 8 & $\mathrm{p}-\mathrm{CF}{ }_{3}$ & 16.7 & 12.2 \\
\hline 9 & $\mathrm{p}-\mathrm{Me}$ & 14.1 & 11.5 \\
\hline 10 & NHC_Me & 18.2 & 15.0 \\
\hline 11 & IPr & 17.8 & 15.2 \\
\hline 12 & NHC_Me $2 \mathrm{sat}$ & 16.9 & 14.2 \\
\hline 13 & NHC_H & 18.8 & 16.0 \\
\hline 14 & NHC.F & 19.2 & 16.4 \\
\hline 15 & NAC & 15.6 & 13.1 \\
\hline
\end{tabular}

Table 1: Computed activation energy barriers using MECP and TS SOC.

We observe that inclusion of SOC effects decreases the activation barrier with respect to MECP energy by about $3 \mathrm{kcal} / \mathrm{mol}$ within the ligand series. The linear correlation found between the two quantities $\left(\mathrm{R}^{2}=0.936\right.$, with only $\mathrm{p}-\mathrm{CF}_{3}$ ligand showing a small deviation from the correlation line) is good, and their proportionality constant $\mathrm{k} \sim 1$ indicates that these effects are systematic throughout the whole spectrum of ligands studied. This finding suggests that inclusion of SOC affects essentially the metal center. To visualize the SOC effects, we computed the electron density difference between the MECP (scalar relativistic, singlet spin state) and the TS (with SOC), and the corresponding isodensities for $\mathrm{L}=\mathrm{NHC} \_\mathrm{Me}_{2}$ are shown in Figure 6 . 

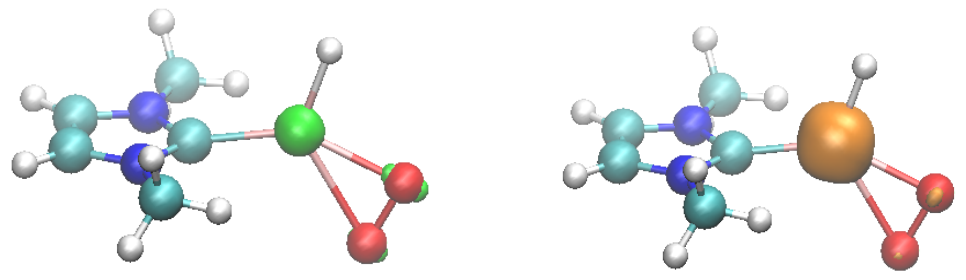

Figure.6: 3D isodensity plot of the electron density change on going from MECP to TS SOC; $\mathrm{L}_{=}=\mathrm{NHC}_{-} \mathrm{Me}_{2}$ at the MECP geometry (isodensity value $\pm 0.0005 \mathrm{e} \mathrm{au}^{-1}$ ). Green (orange) isosurfaces identify regions in which the electron density increases (decreases).

We can easily visualize that both accumulation and depletion rearrangements are localized on gold atom, with a negligible contribution from the oxygen atoms and zero contribution from the ligand. This $\Delta \rho$ rearrangement is consistent with the observed systematic SOC effects which are almost independent from the ligands.

The remarkable ligand effect on the reaction barriers can be usefully exploited in ligand design for this recently discovered oxidative addition reaction on $\mathrm{Au}(\mathrm{I})$-hydride complexes. To this aim, the ligand influence on the electronic structure of the [LAuH] reactants needs to be investigated, which should enable optimization of the $\mathrm{Au}(\mathrm{I})$-hydride moiety for the oxidative addition on a rational basis.

\section{Ligand $\sigma$ donor $/ \pi$ acceptor properties in [LAuH] complexes}

Upon a first inspection of the ligand effect on the activation barriers, we find that more electron donating ligands lower the activation barriers. This result is consistent with the chemical intuition according to which increasing donor character of a ligand increases the electron density at the metal center and favors the oxidative addition. In order to cast this result on a quantitative and predictive ground, we quantified the ability of $\mathrm{L}$ to donate to the metallic fragment by applying the charge-displacement analysis. The plot of the net 
charge donation (CT) from L to AuH fragment against the activation barriers is shown in Figure 7. Results from bond analysis are reported in Table 2.

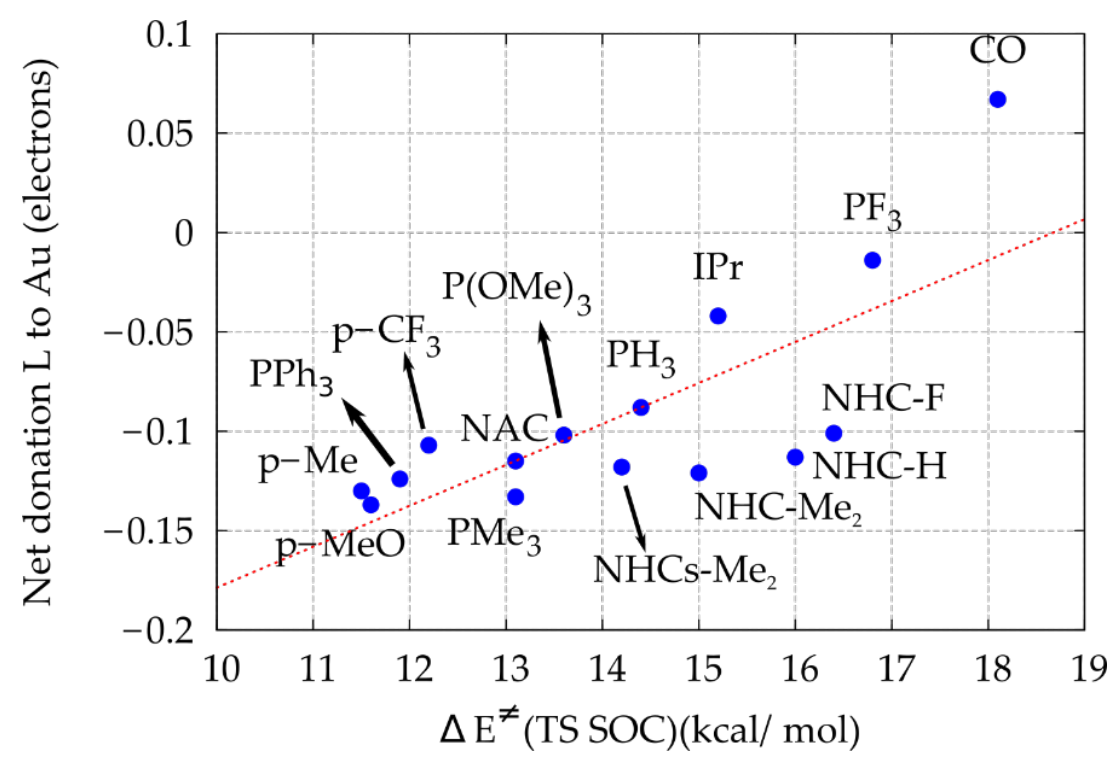

Figure 7: plot of the net charge donation from the ligand to gold fragment (or from gold fragment to ligand for $\mathrm{CO}$ ) $\mathrm{CT}$ versus the activation barriers computed with the TS SOC methodology $\left(\mathrm{R}^{2}=0.572\right)$.

Surprisingly, although a rough trend can be observed (more electron donating ligands actually present lower barriers), the quantitative correlation between the two quantities is very poor $\left(R^{2}=0.572\right)$. The plot in Figure 7 appears rather scattered with some carbenebased ligands lying furthest away from the approximate linear correlation line. We can therefore realize that the bond/reactivity relationship in this case is not as straightforward as one would expect invoking simple chemical reasoning. More in detail, the $\mathrm{CT}$ values of Table 2 are always negative (except for $\mathrm{CO}$ ) indicating that for all ligands a net ligand to metal charge transfer occurs, and, as a general result of this analysis, the electron donor power of the phosphine is larger than that of the carbene ligands. This outcome is not unexpected since it has been also found previously by some of us (see ref. ${ }^{42}$ ). It is interesting to note that $\mathrm{CT}$ varies in the order $\mathrm{PF}_{3}<\mathrm{PH}_{3}<\mathrm{P}(\mathrm{OMe})_{3}<\mathrm{p}-\mathrm{CF}_{3}<\mathrm{PPh}_{3}<\mathrm{p}$ $\mathrm{Me}<\mathrm{PMe}_{3}<$ p-OMe for the phosphine complexes and in the order $\operatorname{IPr}<$ NHC.F $<$ NHC. $\mathrm{H}<\mathrm{NAC}<\mathrm{NHC} \_\mathrm{Me}_{2}$ sat $<\mathrm{NHC} \mathrm{Me}_{2}$ for the carbene ones. However, whereas 
phosphine complexes span a wide range of CTs from -0.014 to $-0.137 \mathrm{e}(0.123 \mathrm{e})$, carbene complexes have relatively similar donating ability, with a CTs ranging from -0.042 to $0.121 \mathrm{e}(0.079 \mathrm{e})$.

In order to shed light on this unexpected result we analyze in more detail the L-AuH bond by applying the recently developed charge-displacement (CD) via Natural Orbitals for Chemical Valence (NOCV) methodology, ${ }^{21} \mathrm{CD}-\mathrm{NOCV}$, as described in Computational details section. This powerful tool allows to quantify the DCD bonding components (within the DCD model, the net charge donation from $\mathrm{L}$ to $\mathrm{AuH}$ is the sum of two contributions, the ligand to metal $\sigma$ donation and the metal to ligand $\pi$ back-donation) and to deeply analyze the coordination bond. The isodensity map for $\Delta \rho$ and the first three NOCV components $\left(\Delta \rho_{1}, \Delta \rho_{2}\right.$, and $\left.\Delta \rho_{3}\right)$ together with the respective CD curves for the L$\mathrm{AuH}$ bond (fragments $\mathrm{L}=\mathrm{NHC} \mathrm{Me}_{2}$ and $[\mathrm{AuH}]$ are used as an illustrative example) are shown in Figure 8.
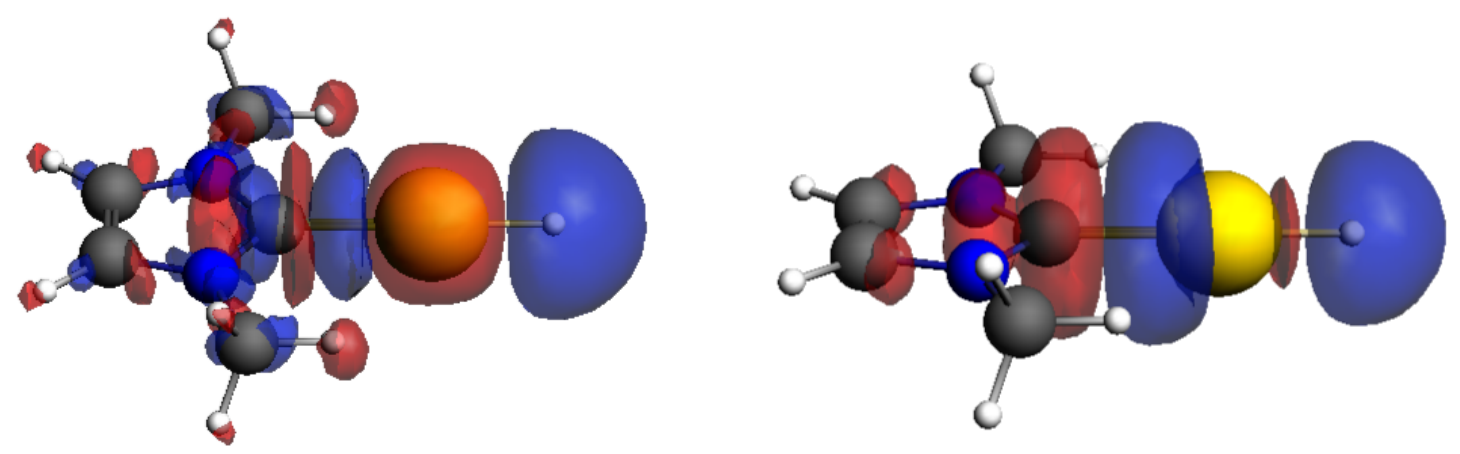

$\Delta \rho$

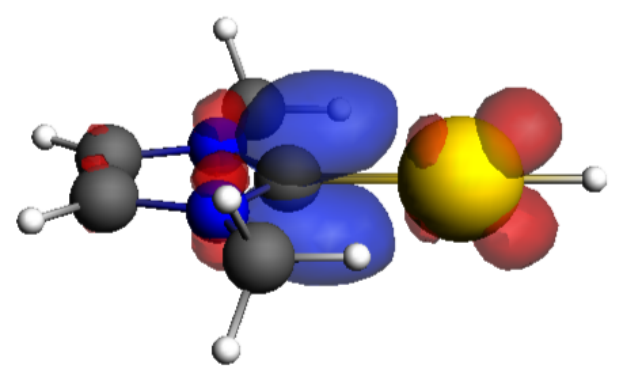

$\Delta \rho_{1}$

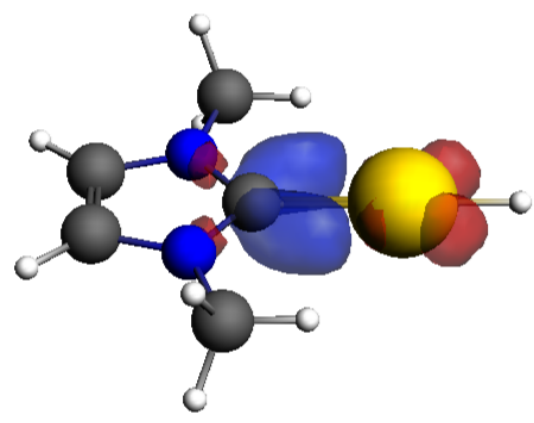




$$
\Delta \rho_{2} \quad \Delta \rho_{3}
$$

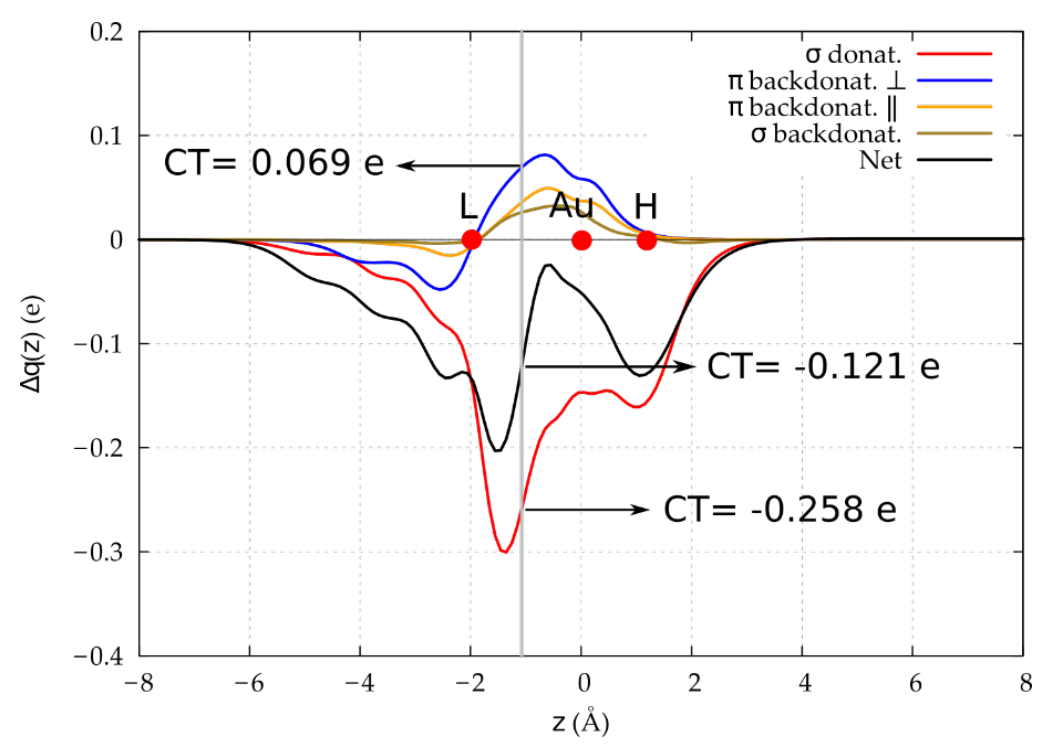

Figure 8: Top) 3D isodensity plot of the electron density change upon formation of L$[\mathrm{AuH}]$ bond and of the first three NOCV components; L=NHC_ $\mathrm{Me}_{2}$ (isodensity value \pm $0.001 \mathrm{e} \mathrm{au}^{-1}$ ). Blue (red) isosurfaces identify regions in which the electron density increases (decreases). Bottom) corresponding CD curves.

\begin{tabular}{|c|c|c|c|c|c|c|}
\hline Entry & Ligand & $\begin{array}{l}\text { CT } \sigma \text { don } \\
\text { (electrons) }\end{array}$ & $\begin{array}{l}\text { CT } \pi \text { back }_{\perp} \\
\text { (electrons) }\end{array}$ & $\begin{array}{l}\text { CT } \pi \text { back } \| \\
\text { (electrons) }\end{array}$ & $\begin{array}{l}\text { CT } \sigma \text { back } \\
\text { (electrons) }\end{array}$ & $\begin{array}{l}\mathrm{CT} \\
\text { (electrons) }\end{array}$ \\
\hline 1 & p-OMe & -0.294 & 0.061 & 0.061 & 0.022 & -0.137 \\
\hline 2 & $\mathrm{PPh}_{3}$ & -0.288 & 0.064 & 0.064 & 0.023 & -0.124 \\
\hline 3 & $\mathrm{PF}_{3}$ & -0.236 & 0.100 & 0.100 & 0.020 & -0.014 \\
\hline 4 & $\mathrm{CO}$ & -0.211 & 0.131 & 0.129 & 0.021 & 0.067 \\
\hline 5 & $\mathrm{PH}_{3}$ & -0.249 & 0.066 & 0.066 & 0.022 & -0.088 \\
\hline 6 & $\mathrm{P}(\mathrm{OMe})_{3}$ & -0.282 & 0.072 & 0.072 & 0.021 & -0.102 \\
\hline 7 & $\mathrm{PMe}_{3}$ & -0.287 & 0.063 & 0.063 & 0.022 & -0.133 \\
\hline 8 & $\mathrm{p}-\mathrm{CF}_{3}$ & -0.279 & 0.068 & 0.068 & 0.023 & -0.107 \\
\hline 9 & p-Me & -0.291 & 0.063 & 0.063 & 0.022 & -0.130 \\
\hline 10 & NHC_Me $\mathrm{Me}_{2}$ & -0.258 & 0.069 & 0.036 & 0.026 & -0.121 \\
\hline 11 & $\mathrm{IPr}$ & -0.258 & 0.078 & 0.031 & 0.036 & -0.042 \\
\hline 12 & $\begin{array}{l}\mathrm{NHC}_{-} \mathrm{Me}_{2} \\
\text { sat }\end{array}$ & -0.266 & 0.082 & 0.024 & 0.031 & -0.118 \\
\hline
\end{tabular}




\begin{tabular}{|l|l|l|l|l|l|l|}
\hline 13 & NHC_H & -0.254 & 0.080 & 0.036 & 0.021 & -0.113 \\
\hline 14 & NHC_F & -0.251 & 0.086 & 0.040 & 0.020 & -0.101 \\
\hline 15 & NAC & -0.272 & 0.086 & 0.025 & 0.030 & -0.115 \\
\hline
\end{tabular}

Table 2: CD-NOCV analysis of the L-AuH bond in [LAuH] complexes.

We see that the net electron density rearrangement $\Delta \rho$ presents a depletion in the NHC carbon atom region and near the gold atom, with accumulation of charge in the NHC-Au bonding area and on the hydride region. Concerning the first NOCV $\Delta \rho_{1}$ component, we observe a marked depletion on $\mathrm{C}$ atom of NHC and accumulation in the NHC-Au bond; this component can be clearly ascribed to the $\sigma$ donation from $\mathrm{NHC} \mathrm{Me}_{2}$ to the metallic fragment $\mathrm{AuH}$. Note that a charge rearrangement within the AuH fragment occurs which can be described as a gold to $\mathrm{H} \sigma$ donation, pointing out to a charge delocalization. The second NOCV component $\Delta \rho_{2}$ shows a depletion on $\mathrm{Au}$ and an accumulation on $\mathrm{C}$ atom perpendicular to the NHC plane; this component can be assigned to the $\pi_{\perp}$ back-donation in the DCD bonding picture. The third component $\Delta \rho_{3}$ is also a $\pi$ back-donation component, but localized parallel to the NHC plane. The fourth component $\Delta \rho_{4}$ (not shown here) represents a small contribution from the $\sigma$ back-donation from $\mathrm{AuH}$ to NHC (see the very small CT values of this component in Table 2). From the CD curves, we can see the charge accumulation in the L-Au bonding region (positive slope) with a net CT of -0.121 electrons (the minus sign indicates flux of charge from left to right, namely from ligand to gold fragment) taken at the isodensity boundary. Concerning the $\sigma$ donation component, a high depletion of electrons in the L region, with a CT $\sigma$ don of -0.258 electrons, is observed. For the perpendicular $\pi$ back-donation we calculate a CT $\pi$ back $\perp$ of 0.069 electrons (from AuH to L). The other two components, i.e. $\pi$ parallel and $\sigma$ backdonation, are small at the isodensity boundary and throughout the molecular region, with correspondingly small CT $\pi$ back $_{\|}$and CT $\sigma$ back values. The same CD-NOCV bond analysis has been applied to all the ligands and results are reported in Table 2.

To explore the effect of the DCD L-AuH bond components on the activation barriers, we correlate the latter with both the $\sigma$ donation and the $\pi$ perpendicular back-donation components. We observe that the $\pi$ parallel back-donation component is almost identical to the $\pi$ perpendicular back-donation for $\mathrm{CO}$ and phosphine-based ligands and much 
smaller for carbene-based ligands and that $\sigma$ back-donation component is almost constant throughout the ligand series (see Table 2). The corresponding plots are shown in Figure 9.
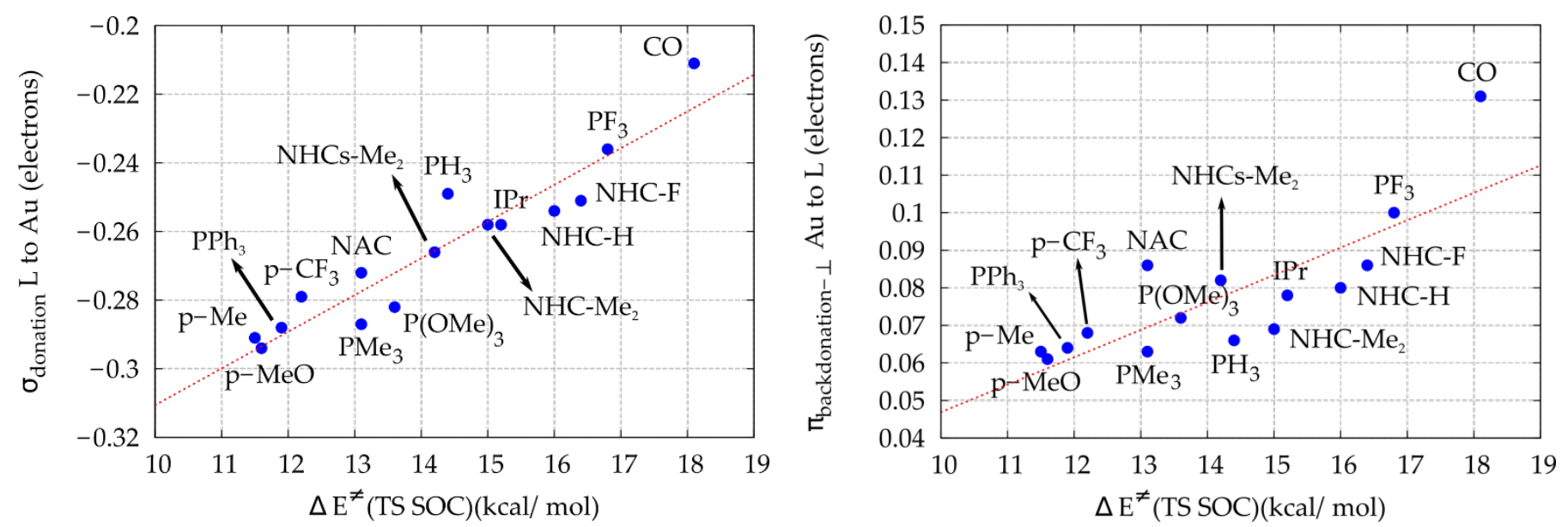

Figure 9: correlation plot of activation barriers $\Delta \mathrm{E}^{\#}$ (TS SOC) vs. left) $\sigma$ donation from $\mathrm{L}$ to $\mathrm{AuH}\left(\mathrm{R}^{2}=0.890\right)$ and right $) \pi$ perpendicular back-donation from $\mathrm{AuH}$ to $\mathrm{L}\left(\mathrm{R}^{2}=0.655\right)$.

We note that the $\sigma$ donation component spans a range of about 0.10 electrons, and the $\pi$ back-donation spans almost the same range (0.07 electrons). Interestingly, the two plots show a nearly acceptable linear correlation between the ligand $\sigma$ donation and the activation barriers $\left(\mathrm{R}^{2}=0.890\right)$ (Figure 9 left) and a weak one between the AuH $\pi$ backdonation (or ligand acceptor ability) and the activation barriers $\left(\mathrm{R}^{2}=0.655\right)$ (Figure 9 right). Comparison between Figure 9 and Figure 7 would suggest that the scattered ligand effect on the activation barrier has its origin in the AuH to $\mathrm{L} \pi$ back-donation component. The finding that data points in Figure 7 and in Figure 9 appear to be randomly distributed inspired us to separate the ligand series into two subsets: the phosphine-based and the carbene-based ligands, including $\mathrm{CO}$ in the phosphine subset (CO more naturally follows the phosphine subset trend).

Corresponding plots of activation barriers and both the $\sigma$ donation and the $\pi$ perpendicular back-donation components of the L-AuH bond have been constructed separately for the phosphine-based and carbene-based ligand subsets, and are shown in Figures 10 and 11. 

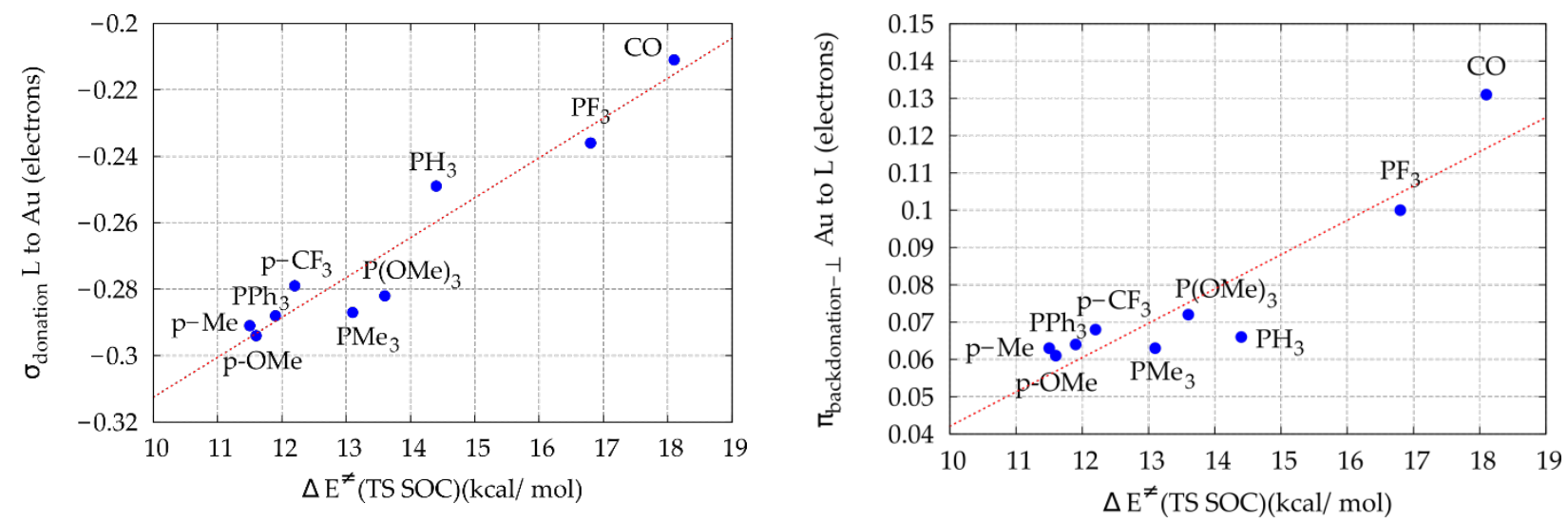

Figure 10: correlation plot of activation barriers $\Delta \mathrm{E}^{\#}$ (TS SOC) vs. left) $\sigma$ donation from $\mathrm{L}$ to $\mathrm{AuH}\left(\mathrm{R}^{2}=0.925\right)$ and right) $\pi$ perpendicular back-donation from $\mathrm{AuH}$ to $\mathrm{L}$ $\left(\mathrm{R}^{2}=0.846\right), \mathrm{L}=\mathrm{p}-\mathrm{OMe}, \mathrm{PPh}_{3}, \mathrm{PF}_{3}, \mathrm{PH}_{3}, \mathrm{P}(\mathrm{OMe})_{3}, \mathrm{PMe}_{3}, \mathrm{p}-\mathrm{CF}_{3}, \mathrm{p}-\mathrm{Me}$ and $\mathrm{CO}$
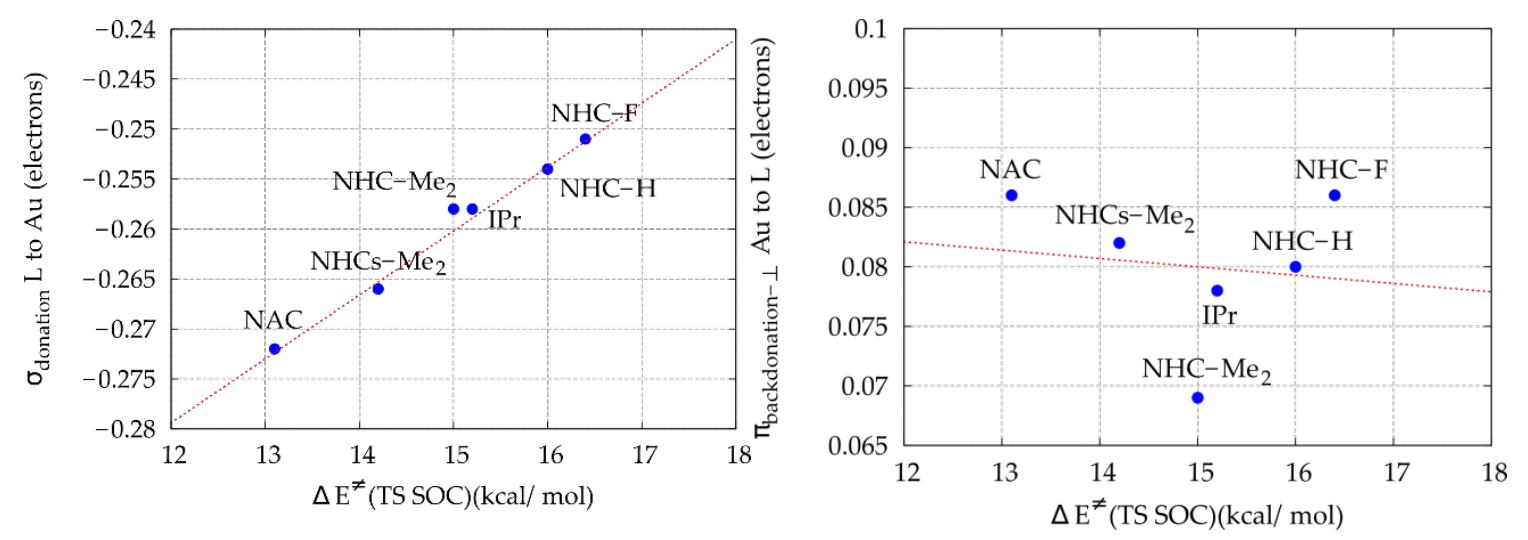

Figure 11: correlation plot of activation barriers $\Delta \mathrm{E}^{\#}$ (TS SOC) vs. left) $\sigma$ donation from $\mathrm{L}$ to $\mathrm{AuH}\left(\mathrm{R}^{2}=0.984\right)$ and right) $\pi$ perpendicular back-donation from $\mathrm{AuH}$ to $\mathrm{L}$ $\left(\mathrm{R}^{2}=0.017\right), \mathrm{L}=\mathrm{NHC} \_\mathrm{Me}_{2}, \mathrm{IPr}, \mathrm{NHC} \_\mathrm{Me}_{2}$ sat, NHC_H, NHC_F, NAC.

We find that in each ligand subset a very good linear relationship exists between the activation barriers and the $\sigma$ donation component of the L-AuH bond (note that for phosphine-type ligands $\mathrm{R}^{2}=0.925$ and for carbene-type ligands $\mathrm{R}^{2}=0.984$ ), showing the 
expected trend, i.e. the barrier increases when the electron-donating power of L (as measured by the CT $\sigma$ don) decreases. An acceptable good relationship is found between the activation barriers and the $\pi$ back-donation component of the L-AuH bond in the phosphine subset $\left(\mathrm{R}^{2}=0.846\right)$, whereas no linear correlation is observed in the carbenesubset $\left(\mathrm{R}^{2}=0.017\right)$, where the activation barrier is found to be completely independent from the $\pi$ back-donation. For instance, a similar AuH basicity within the carbene ligand subset (a CT $\pi$ back $_{\perp}$ value of $0.086 \mathrm{e}$ ) gives rise to a barrier which is either low (13.1 $\mathrm{kcal} / \mathrm{mol}$ for NAC) or high (16.4 kcal/mol for NHC_F $)$. However, a closer inspection of Figure 11 right) reveals that if we further separate the carbene-based ligands in the $\mathrm{L}=$ NHC_ $\mathrm{Me}_{2}, \mathrm{IPr}, \mathrm{NHC} \_\mathrm{H}, \mathrm{NHC} \_\mathrm{F}$ and $\mathrm{L}=\mathrm{NHC} \mathrm{Me}_{2}$ sat, NAC subgroups, the first subgroup shows a positive correlation with $\mathrm{R}^{2}=0.808$, suggesting that the activation barrier depends on the $\pi$ back-donation differently for saturated NHC ligand structures and for unsaturated NHC or NAC ligand structures. We would like to mention here that in 2011 Comas-Vives and Harvey argued that diaminocarbenes were surprisingly good $\pi$ acceptor ligands in a range of metal complexes, where the metal to diaminecarbene $\pi$ back-bonding contribution was calculated to be comparable or larger than that obtained with phosphanes. ${ }^{43}$

From this CD-NOCV analysis we gathered the interesting results that: i) the ligand effect on the oxidative addition of $\mathrm{O}_{2}$ on $[\mathrm{LAuH}]$ complexes cannot be easily rationalized only on the basis of the L-AuH DCD bond components, depending on the ligand nature; ii) within a ligand subset, either carbene- or phosphine-type ligand, the $\sigma$ donation component of the L-AuH bond appears as the driving factor in determining the amount of the activation barriers, namely the barrier decreases with the ligand $\sigma$ donor ability increasing, and it can be indeed considered as a suitable descriptor of the activation energy barrier with good approximation; iii) concerning the correlation between the $\pi$ back-donation component of the L-AuH bond and the activation energy barrier, although for the phosphine-type ligands the trend is the expected one (i.e., the barrier decreases with the ligand $\pi$ acceptor ability decreasing), for the carbene-type ligand the pattern is totally unexpected.

Now the question is, what does the "anomalous" behavior of carbene complexes stem from? 
The reason for that could be related to the DCD model poor transferability from the linear $[\mathrm{LAuH}]$ complexes to the corresponding trigonal $\left[\mathrm{LAuH}\left(\mathrm{O}_{2}\right)\right]$ transition state structures for carbene-based ligands. It is worth noting that, upon inspection of the TS SOC geometries in the carbene series, the AuCNN dihedral angle is not $180^{\circ}$ as measured in the $[\mathrm{LAuH}]$ complexes but decreases to $169.2^{\circ}$ (NAC), $168.9^{\circ}$ (NHC_Me2 sat), $170.5^{\circ}$ (NHC_Me2), $163.9^{\circ}\left(\mathrm{NHC} \_\mathrm{F}\right), 166.8^{\circ}\left(\mathrm{NHC} \_\mathrm{H}\right)$ and $171.1^{\circ}$ (IPr), which would signal a different role of the back-donation from the metal fragment to the ligand (or, alternatively, of the electron acceptor properties of the ligands).

In order to gain insights into this unexpected result, we looked at the electron density rearrangement in the TS structure through the CD-NOCV analysis using $\mathrm{L}$ and $\operatorname{AuH}\left(\mathrm{O}_{2}\right)$ as fragments. Obviously, due to the non linear geometry of this structure, we cannot divide the $\mathrm{L}-\mathrm{AuH}\left(\mathrm{O}_{2}\right)$ bond in $\sigma$ and $\pi$ contributions; however, we can get a qualitative view of how and if the gold fragment back-donation to ligand description can be transferred from the initial $[\mathrm{LAuH}]$ complexes to the corresponding $\left[\operatorname{LAuH}\left(\mathrm{O}_{2}\right)\right]$ transition states. For the $\mathrm{L}-\mathrm{AuH}\left(\mathrm{O}_{2}\right)$ bond analysis in the TS structures we selected three prototype carbene-based ligands, $\mathrm{NHC}_{-} \mathrm{H}, \mathrm{IPr}$ and $\mathrm{NAC}$, focusing on the $\mathrm{NHC}_{-} \mathrm{H}$ carbene as an illustration. The isodensity surfaces for the first four NOCV components of $\Delta \rho$ are depicted in Figure 12 (the corresponding isodensity surfaces for IPr and NAC are depicted in Figure S1 and S2 in the ESI). All the other NOCV contributions are very small or zero and are not considered. The $\Delta \rho_{1}$ component shows a depletion at the NHC_H (particularly at the carbon atom) and an accumulation at the $\operatorname{AuH}\left(\mathrm{O}_{2}\right)$ moiety with an electronic redistribution within the metallic fragment revealing depletion at the outer region of gold (towards $\mathrm{H}$ and $\mathrm{O}_{2}$ ) and accumulation in the region between gold and $\mathrm{O}_{2}$, on the $\mathrm{O}_{2}$ and on the $\mathrm{H}$ atom: it represents the charge donation from NHC_H to $\operatorname{AuH}\left(\mathrm{O}_{2}\right)$ fragment which largely delocalizes, within the $\operatorname{AuH}\left(\mathrm{O}_{2}\right)$ fragment, from gold to $\mathrm{O}_{2}$ and $\mathrm{H}$. The $\Delta \rho_{2}$ component shows depletions on $\mathrm{O}_{2}$ and $\mathrm{Au}$ and accumulation on $\pi$ empty orbital of the carbene carbon: it describes the back-donation from $\operatorname{AuH}\left(\mathrm{O}_{2}\right)$ to NHC_H perpendicularly to the NHC_H plane. Noticeably, the electron density transferred back to the NHC_H ligand has mainly its origin in the $\mathrm{O}_{2}$ moiety and much less in the d orbitals of gold. Such pseudo back-bonding interactions in NHC complexes have been observed experimentally several times with $\mathrm{d}^{0}$ metals ${ }^{44}$ and computationally with $\left[\mathrm{LTiCl}_{4}\right]$ complexes. ${ }^{45}$ In our case, however, since we are dealing with an electron rich $\mathrm{d}^{8} / \mathrm{d}^{10}$ metal, it arises from the bent "trigonal" geometry of the TS structures which 
reduces the ligand $\mathrm{L}$ interaction with the gold $\mathrm{d}$ orbital commonly involved in the $\pi$ backdonation in linear complexes, making the back-donation in $\left[\operatorname{LAuH}\left(\mathrm{O}_{2}\right)\right]$ markedly different from that occurring in $[\mathrm{LAuH}]$ complexes. This metal ligand cooperativity has been also reported in the literature for the activation of $\mathrm{O}_{2}$ using Pt complexes. ${ }^{46}$

The $\Delta \rho_{3}$ component depicts small depletion on gold and accumulation on Au-C (carbene) bond: it describes the back-donation from gold to NHC_H. Finally, the $\Delta \rho_{4}$ component shows a depletion on a d filled orbital of $\mathrm{Au}$ atom and an increase of electron density on the Au-C (carbene) bond (mostly on carbon atom) in the plane of NHC_H. Interestingly, only in the first two NOCV components related to donation $\left(\Delta \rho_{1}\right)$ and back-donation $\left(\Delta \rho_{2}\right)$ both carbene ligand $\mathrm{NHC}_{-} \mathrm{H}$ and $\mathrm{O}_{2}$ fragments are involved. Visual inspection of the $\Delta \rho_{1}$ and $\Delta \rho_{2}$ reveals a very similar topology to that of $\Delta \rho_{1}$ ( $\sigma$ donation) and $\Delta \rho_{2}(\pi$ back-donation), respectively, in the corresponding [NHC_HAuH] complex (see Figure 8). However, although the donation component $\Delta \rho_{1}$, mainly involving charge donation from $\mathrm{L}$ to gold fragment as shown in both Figure 8 and 12, appears to be transferable from [NHC_HAuH] to [NHC_HAuH $\left(\mathrm{O}_{2}\right)$ ] to a good approximation (apart from the additional delocalization into the $\mathrm{O}_{2}$ fragment observed in [NHC_HAuH $\left.\left(\mathrm{O}_{2}\right)\right]$ ) the back-donation component $\Delta \rho_{2}$ does not. As a matter of fact, whereas $\Delta \rho_{2}$ mainly involves Au to L backdonation in Figure 8, it mainly involves $\mathrm{O}_{2}$ to $\mathrm{L}$ charge back-donation in Figure 12. These findings are consistent with the erratic trend observed above between the back-donation component in $[\mathrm{L}-\mathrm{AuH}]$ and the activation energy barrier (Figure 11 right).

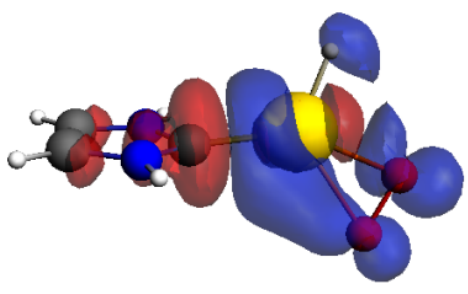

$\Delta \rho_{1}$

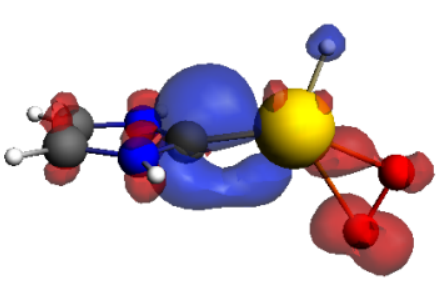

$\Delta \rho_{2}$ 


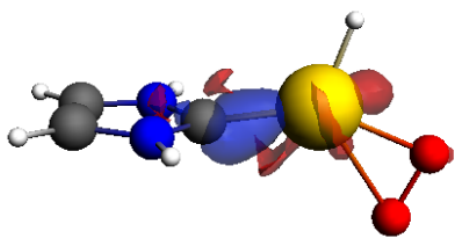

$\Delta \rho_{3}$

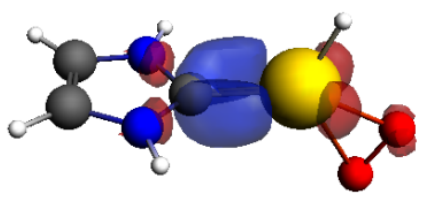

$\Delta \rho_{4}$

Figure 12: 3D isodensity plot of the electron density change upon formation of L- $\left[\mathrm{AuH}\left(\mathrm{O}_{2}\right)\right]$ bond and of the first four NOCV components; $\mathrm{L}=\mathrm{NHC} \_\mathrm{H}$ (isodensity value $\pm 0.001 \mathrm{e} \mathrm{au}^{-1}$ ). Blue (red) isosurfaces identify regions in which the electron density increases (decreases).

To further support the donation/back-donation transferability/non-transferability issue, it is useful to assign an energy contribution to each NOCV pair. Inspection of Table S1 in the ESI, where decomposition energy contributions characterizing the donation and backdonation interactions are reported for the three [LAuH] complexes and their corresponding $\left[\mathrm{LAuH}\left(\mathrm{O}_{2}\right)\right]$ transition states, shows that the largest contribution to the L$\mathrm{AuH}$ or $\mathrm{L}-\mathrm{AuH}\left(\mathrm{O}_{2}\right)$ bond is the ligand to $\mathrm{AuH}$ or $\mathrm{AuH}\left(\mathrm{O}_{2}\right)$ donation. Interestingly, the energy trend is the same for both $[\mathrm{LAuH}]$ and $\left[\mathrm{LAuH}\left(\mathrm{O}_{2}\right)\right]$ series, i.e. NHC_H $<\mathrm{IPr} \leq$ NAC, although in absolute value the $\Delta \rho_{1}$ donation energy contributions are larger for the latter. This is expected since the ligand charge donation is much enhanced in the TS structures by the charge delocalization within the $\operatorname{AuH}\left(\mathrm{O}_{2}\right)$ fragment (through $\mathrm{Au}$ to $\mathrm{O}_{2}$ and $\mathrm{Au}$ to $\mathrm{H}$ donation, see Figure 12). On the contrary, the $\mathrm{AuH}$ or $\mathrm{AuH}\left(\mathrm{O}_{2}\right)$ to L backdonation energy contributions do not show the same trend for the [LAuH] complexes and their corresponding transition states $\left[\mathrm{LAuH}\left(\mathrm{O}_{2}\right)\right]$. 
In conclusion, this analysis reveals the presence of a non-negligible direct and/or metal mediated interaction between dioxygen and ligand in the $\left[\mathrm{LAuH}\left(\mathrm{O}_{2}\right)\right]$ transition states, so that the acceptor properties of the carbene in the $[\mathrm{LAuH}]$ reactant complexes are not good quantitative descriptors of the ligand effect on the oxidative addition activation barrier energies.

\section{Conclusions}

In the present work we have extended our previous study on the oxidative addition of $\mathrm{O}_{2}$ into the $\mathrm{Au}-\mathrm{H}$ bond8 by exploring the ligand effect on the activation barriers for fifteen different ancillary ligands in [LAuH] complexes, both using the MECP and the TS SOC approaches. The analyzed ligands produce a range of $\Delta \mathrm{E}^{\neq}$of about $7 \mathrm{kcal} / \mathrm{mol}$, which should have a deep impact in modulating experimental reaction rates. We further corroborate here our finding that the reaction of $\mathrm{O}_{2}$ with [LAuH] occurs through the oxidative addition mechanism and we predict that the use of an electron donating phosphine ligand accelerate the reaction. This finding is bound to have important implications in the oxidative addition reaction with gold hydride complexes. Inclusion of SOC effects for the TS search lowers systematically the activation barriers by about 3 $\mathrm{kcal} / \mathrm{mol}$ with respect to the MECP values independently from the ligand-type. We show that the net electron donor character of the ligand affects the activation barriers differently in the carbene and phosphine ligand subsets, although as a rough systematic trend more electron donating ligands present lower barriers. On a quantitative ground, however, the CD-NOCV bond analysis applied to $[\mathrm{LAuH}]$ complexes reveal that for both ligand-type only the $\sigma$ donation component of the L-AuH bond accounts for the ligand effect on the activation energy barriers, whereas for carbene-type ligands the $\pi$ back-donation component is not a suitable reactivity descriptor. The reason for that might rely on the non-transferability of the information acquired on the $\pi$ acceptor properties of the carbene ligand in the linear $[\mathrm{LAuH}]$ complexes to the trigonal transition state $\left[\mathrm{LAuH}\left(\mathrm{O}_{2}\right)\right]$ structures, where the $\mathrm{O}_{2}$ moiety appears to be involved in the back-donation to the ligand. These results demonstrate the complexity of the ligand effect for this reaction, which cannot be fully quantitatively rationalized on the basis of the ligand electronic properties in the $[\mathrm{LAuH}]$ complexes. However, it is important to underline that for ligand design 
purpose, the $\sigma$ donor ability of the ligand in the $[\mathrm{LAuH}]$ complexes could represent a reliable, quantitative and general reactivity descriptor.

\section{Acknowledgements}

C.A.G., J.N.H. and P.B. gratefully acknowledge the COST Action CM1305 (ECOSTBio) "Explicit Control Over Spin-states in Technology and Biochemistry". L.B. and F.T. acknowledge Ministero dell'Istruzione, Università e Ricerca (MIUR) for financial support through the FIRB Futuro in Ricerca project no. RBFR1022UQ. C.A.G., F.T. and P.B. acknowledge Ministero dell'Istruzione, Università e Ricerca (MIUR) for financial support through the "Fondo d'Ateneo per la Ricerca di Base 2015" - project "Studio teorico di complessi di $\mathrm{Au}(\mathrm{I})$ per la catalisi omogenea e di aggregati prototipo contenenti il legame alogeno".

\section{Notes and references}

\footnotetext{
${ }^{1}$ E.Y. Tsui, P. Müller, J.P. Sadighi, Angew. Chem., Int. Ed., 2008, 47, 8937.

2 D.A. Roşca, D.A. Smith, D.L. Hughes, M. Bochmann, Angew. Chem., Int. Ed., 2012, 51, 10643.

${ }^{3}$ M. -J. Crawford, T.M. Klapötke, Angew. Chem., Int. Ed., 2002, 41, 2269.

${ }^{4}$ H. Schmidbaur, H.G. Raubenheimer, L. Dobrzanska, Chem. Soc. Rev., 2014, 43, 345.

${ }^{5}$ A. Tamaki, J. Kochi, J. Organomet. Chem., 1973, 61, 441.

${ }^{6}$ D. A. Roşca, J. Fernandez-Cestau, D. L. Hughes and M. Bochmann, Organometallics, 2015, 34, 2098.

${ }^{7}$ E.Y. Tsui, P. Müller and J.P. Sadighi, Angew. Chem. Int. Ed., 2008, 47, 8937.

${ }^{8}$ C. A. Gaggioli, L. Belpassi, F. Tarantelli, D. Zuccaccia, J. N. Harvey and P. Belanzoni, Chem. Sci., 2016, 7, 7034.

9 J.N. Harvey, WIREs Comput. Mol. Sci., 2014, 4, 1.

${ }^{10}$ M. Joost, A. Amgoune and D. Bourissou, Angew. Chem. Int. Ed., 2015, 54, 15022.

11 J.H. Teles, Angew. Chem., Int.Ed., 2015, 54, 5556.

12 P.S.D. Robinson, G.N. Khairallah, G. da Silva, H. Lioe, R.A.J. O'Hair, Angew. Chem. Int.Ed., 2012, 51, 3812.

${ }^{13}$ M. Joost, P. Gualco, Y. Coppel, K. Miqueu, C.E. Kefalidis, L. Maron, A. Amgoune, D. Bourissou, Angew. Chem. Int. Ed., 2014, 53, 747.

${ }^{14}$ C. - Y. Wu, T. Horibe, C.B. Jacobsen, F.D. Toste, Nature, 2015, 517, 449.

${ }^{15}$ M.C. Gimeno, A. Laguna, Chem. Rev. 1997, 97, 511.

${ }^{16}$ O. Crespo, M.C. Gimeno, A. Laguna, P.G. Jones, J. Chem. Soc. Dalton Trans., 1992, 1601.

${ }^{17}$ M. Joost, A. Zeineddine, L. Estévez, S. Mallet-Ladeira, K. Miqueu, A. Amgoune, D. Bourissou, J. Am. Chem. Soc., 2014, 136, 14654.

18 J. -H. Zhan, H. Lv, Y. Yu, J. -L. Zhang, Adv. Synth. Catal., 2012, 354, 1529.

${ }^{19}$ I. Fernández, L.P. Wolters, F.M. Bickelhaupt, J. Comput. Chem., 2014, 35, 2140.
} 
${ }^{20}$ M. Joost, L. Estévez, K. Miqueu, A. Amgoune, D. Bourissou, Angew. Chem. Int. Ed., 2015, 54, 5236.

${ }^{21}$ G. Bistoni, S. Rampino, F. Tarantelli and L. Belpassi, J. Chem. Phys., 2015, 142, 084112.

22 (a) G. Te Velde, F. M. Bickelhaupt, E. J. Baerends, C. Fonseca Guerra, S. J. A. van Gisbergen, J.G. Snijders and T. Ziegler, J. Comput. Chem., 2001, 22, 931; (b) C. Fonseca Guerra, J.G. Snijders, G. te Velde and E.J. Baerends, Theor. Chem. Acc., 1998, 99, 391; (c) ADF2012.01, SCM, Theoretical Chemistry, Vrije Universiteit, Amsterdam, The Netherlands, http://www.scm.com.

${ }^{23}$ (a) A. D. Becke, Phys. Rev. A, 1988, 38, 3098; (b) J. P. Perdew and Y. Wang, Phys. Rev. B, 1986, 33, 8800; Phys. Rev. B, 1989, 40, 3399.

${ }^{24}$ S. Grimme, S. Ehrlich and L. Goerigk, J. Comput.Chem., 2011, 32, 1456.

${ }^{25}$ (a) E. van Lenthe, E. J. Baerends and J. G. Snijders, J. Chem. Phys., 1993, 99, 4597; (b) E. van Lenthe, E. J. Baerends and J. G. Snijders, J. Chem. Phys., 1994, 101, 9783; (c) E. van Lenthe, R. van Leeuwen, E. J.

Baerends and J.G. Snijders, Int. J. Quantum Chem., 1996, 57, 281; (d) E. van Lenthe, J.G. Snijders and E.J. Baerends, J. Chem. Phys., 1996, 105, 6505.

${ }^{26}$ J. N. Harvey, M. Aschi, H. Schwarz and W. Koch, Theor. Chem. Acc., 1998, 99, 95.

${ }^{27}$ L. Belpassi, I. Infante, F. Tarantelli and L. Visscher, J. Am. Chem. Soc., 2008, 130, 1048.

${ }^{28}$ D. Marchione, L. Belpassi, G. Bistoni, A. Macchioni, F. Tarantelli and D. Zuccaccia, Organometallics, 2014, 33, 4200.

${ }^{29}$ K.M. Azzopardi, G. Bistoni, G. Ciancaleoni, F. Tarantelli, D. Zuccaccia and L. Belpassi, Dalton Trans., 2015, 44, 13999.

${ }^{30}$ N. Salvi, L. Belpassi and F. Tarantelli, Chem. Eur. J., 2010, 16, 7231.

${ }^{31}$ D. Zuccaccia, L. Belpassi, L. Rocchigiani, F. Tarantelli and A. Macchioni, Inorg. Chem., 2010, 49, 3080.

${ }^{32}$ G. Bistoni, L. Belpassi and F. Tarantelli, Angew. Chem. Int. Ed., 2013, 52, 11599.

${ }^{33}$ (a) M. Mitoraj and A. Michalak, J. Mol. Model., 2007, 13, 347; (b) A. Michalak, M. Mitoraj and T. Ziegler, J. Phys. Chem. A, 2008, 112, 1933.

${ }^{34}$ (a) A. Michalak, R.L. De Kock and T. Ziegler, J. Phys. Chem. A, 2008, 112, 7256; (b) R.F. Nalewajski and J. Mrozek, Int. J. Quantum Chem., 1994, 51, 187; (c) R.F. Nalewajski, J. Mrozek and A. Michalak, Int. J. Quantum Chem., 1997, 61, 589.

35 M.P. Mitoraj, A. Michalak and T. Ziegler, J. Chem. Theory Comput., 2009, 5, 962.

${ }^{36}$ L. Biasiolo, L. Belpassi, C.A. Gaggioli, A. Macchioni, F. Tarantelli, G. Ciancaleoni, and D. Zuccaccia, Organometallics, 2016, 35, 595.

${ }^{37}$ C.A. Gaggioli, G. Bistoni, G. Ciancaleoni, F. Tarantelli, L. Belpassi and P. Belanzoni, Chem. Eur. J., 2017, 23, 7558.

${ }^{38}$ D. Marchione, M.A. Izquierdo, G. Bistoni, R.W.A. Havenith, A. Macchioni, D. Zuccaccia, F. Tarantelli and L. Belpassi, Chem. Eur. J., 2017, 23, 2722.

${ }^{39}$ W. Wang, G. B. Hammond and B. Xu, J. Am. Chem. Soc., 2012, 134, 5697.

${ }^{40}$ C.A. Gaggioli, G. Ciancaleoni, D. Zuccaccia, G. Bistoni, L. Belpassi, F. Tarantelli and P. Belanzoni, Organometallics, 2016, 35, 2275.

${ }^{41}$ L. D' Amore, G. Ciancaleoni, L. Belpassi, F. Tarantelli, D. Zuccaccia and P. Belanzoni, Organometallics, 2017, accepted.

${ }^{42}$ G. Ciancaleoni, N. Scafuri, G. Bistoni, A. Macchioni, F. Tarantelli, D. Zuccaccia and L. Belpassi, Inorg. Chem., 2014, 53, 9907.

${ }^{43}$ A. Comas-Vives and J.N. Harvey, Eur. J. Inorg. Chem., 2011, 5025.

44 (a) C.D. Abernethy, G.M. Codd, M.D. Spicer and M.K. Taylor, J. Am. Chem. Soc., 2003, 125, 1128; (b) P. Shukla, J.A. Johnson, D. Vidovic, A.H. Cowley and C.D. Abernethy, Chem. Commun., 2004, 360; (c) S.A. Mungur, A.J. Blake, C. Wilson, J. McMaster and P.L. Arnold, Organometallics, 2006, 25, 1861; (d) J. Li, C. Schulzke, S. Merkel, H.W. Roesky, P.P. Samuel, A. Döring and D. Stalke, Z. Anorg. Allg. Chem., 2010, 636, 511.

${ }^{45}$ J.C. Bernhammer, G. Frison and H.V. Huynh, Chem. Eur. J., 2013, 19, 12892.

${ }^{46}$ (a) M.L. Scheuermann, U. Fekl, W. Kaminsky and K.I. Goldberg, Organometallics, 2010, 29, 4749; (b) M.L. Scheuermann, A.T. Luedtke, S.K. Hanson, U. Fekl, W. Kaminsky and K.I. Goldberg, Organometallics, 2013, 32, 4752; (c) M.L. Scheuermann and K.I. Goldberg, Chem. Eur. J., 2014, 20, 14556. 
